Supporting Information

\title{
SYNTHESIS OF PORRITOXIN
}

\author{
Ivan Cornella and T. Ross Kelly*
}

S2. ${ }^{1}$ H NMR Porritoxin (3)

S3. ${ }^{13}$ C NMR Porritoxin (3) 